\title{
PENGARUH MOTIVASI TERHADAP HASIL BELAJAR SISWA IPA DI SMAN 6 MUARO JAMBI
}

\author{
Wita Ardina Putri ${ }^{1}$, Riska Fitrini ${ }^{2}$, Endah Febri Setya Rini ${ }^{3}$, Febri Tia Aldila ${ }^{4}$, Tri Ratnawati ${ }^{5}$ \\ Program Pendidikan Fisika, Universitas Jambi ${ }^{1,2,3,4,5}$ \\ Email: witaardinaputri09@gmail.com ${ }^{1}$
}

\begin{abstract}
Abstrak
Motivasi belajar merupakan dorongan yang diberikan oleh seseorang untuk orang lain agar dapat mencapai tujuan yang ingin dicapai. Lemahnya motivasi belajar peserta didik dapat menurunkan hasil belajar peserta didik. Jadi dapat dikatakan bahwa motivasi belajar merupakan salah satu faktor yang dapat mempengaruhi hasil belajar peserta didik. Adapun tujuan dari dilakukan penelitian ini yaitu untuk mengetahui pengaruh dari motivasi belajar terhadap hasil belajar peserta didik terhadap mata pelajaran fisika pada materi gerak lurus di SMA N 6 Muaro Jambi. Metode yang digunakan dalam penelitian ini ialah penelitian kuantitatif dan penelitian survey. Subjek dari penelitian ini yaitu siswa kelas X IPA tahun ajaran 2019/2020 yang berjumlah 50 orang. Instrumen yang digunakan yaitu berupa kuisioner tentang motivasi serta soal pilihan ganda tentang materi gerak lurus. Hasil yang diperoleh dari penelitian ini yaitu motivasi belajar peserta didik tergolong dalam kriteria tinggi atau baik dengan presentase $78 \%$. Sedangkan hasil belajar pesera didik pada mata pelajaran fisika materi gerak lurus berada pada kategori cukup baik dengan presentasi $82 \%$. Berdasarkan uji regresi yang bertujuan untuk mengetahui pengaruh motivasi belajar terhadap hasil belajar menunjukkan bahwa terdapat pengaruh yang baik dan positif antara motivasi dan hasil belajar siswa di SMAN 6 Muaro Jambi.
\end{abstract}

Kata Kunci : Motivasi Belajar, Hasil Belajar, Fisika, SMA N 6 Muaro Jambi

\begin{abstract}
Motivation to learn is an encouragement given by someone to others in order to achieve their goals. Weak students' motivation can reduce students' learning outcomes. So it can be said that learning motivation is one of the factors that can affect student learning outcomes. Hence, the purpose of this study is to discover the effect of learning, motivation on student learning outcomes in physics subjects in straight motion material at SMA $N 6$ Muaro Jambi.This research utilized quantitative research methods with surveys. The subjects of this study were students of class X IPA school year 2019/2020 consisting of 50 people. The instrument used was a questionnaire about motivation and multiple choice questions about straight motion material. The result obtained from this study was the learning motivation of students was classified as high or good criteria. Student learning outcomes in the physics subject matter of straight motion were in the fairly good category. Based on the regression test which aimed at determining the effect of learning, motivation on learning outcomes, it was discovered that there was a good and positive influence between motivation and student learning outcomes at SMAN 6 Muaro Jambi.
\end{abstract}

Key Words : learning motivation, learning outcomes, physics, SMA N 6 Muaro Jambi

\section{PENDAHULUAN}

Pendidikan memiliki peranan yang sangat penting dalam meningkatkan kualitas sumber daya manusia yang berkualitas serta untuk kelangsungan hidup suatu bangsa atau Negara [1]. Karena sumber daya manusia yang berkualitas bisa dilihat dari penguasaan ilmu ataupun dari karakter peserta didik tersebut [2]. Mengapa dapat dikatakan demikian? Dikarenakan dengan pendidikan seseorang dapat meletakan dirinya sesuai dengan lingkungan masyarakat maupun lingkungan keluarga [3].

Jadi pendidikan juga harus bisa membawa perubahan dan perkembangan yang sejalan dengan perubahan budaya [4]. Pendidikan juga merupakan suatu jalan untuk mempengaruhi peserta didik agar dapat 
menyesuaikan dirinya selayak mungkin di lingkungannya [5]. Pendidikan juga merupakan salah satu kegiatan yang sangat penting bagi semua manusia [6]. Karena pendidikan dapat meningkatkan kualitas sumber daya manusia [7]. Selain itu menurut UU No 20 tahun 2003 pendidikan merupakan suatu usaha yang dilakukan secara sadar dan sudah terencana untuk mencapai suasana belajar dan proses pembelajaran agar siswa secara aktif dapat mengembangan potensi yang dimilikinya [8]. Pendidikan juga merupakan ujung tombak dalam proses mengembangkan sumber daya manusia sehingga pendidikan berperan aktif dalam meningkatkan kualitas dan kuantitas pola berpikir siswa [9].

Menurut permendiknas nomor 41 tahun 2007, menyatakan bahwa materi ajar memuat fakta, konsep, prinsip serta prosedur yang relevan ditulis dalam bentuk butira-butiran sesuai dengan rumusan indikator pencapaian kompetensi [10]. Usaha manusia dalam memahami alam semesta melalui penyelidikan merupakan arti dari ilmu pengetahuan alam [11]. Ilmu pengetahuan alam atau yang biasa disebut IPA merupakan suatu kumpulan ilmu-ilmu yang serumpun dan berupaya untuk menjelaskan semua fenomena yang terjadi di alam [12].

Salah satu bagian dari IPA yaitu ilmu fisika. Ilmu fisika dapat dikatakan sebagai ilmu pengetahuan yang bisa menerangkan tentang gejala alam itu sendiri [13]. Fisika merupakan bagian dari ilmu yang identik dengan peristiwa serta fenomena alam, sehingga sangat penting untuk di pelajari [14]. Fisika merupakan salah satu ilmu yang mempelajari materi dan energi yang ada di dalamnya [15].

Ilmu fisika dapat dikatakan sebagai ilmu studi empiris, dimana artinya apa saja yang berkaitan dengan perilakunya di pelajari melalui pengamatan [16]. Ilmu fisika juga merupakan ilmu yang bertujuan untuk mendidik peserta didik agar dapat berpikir logis, kritis, dan memiliki sifat objektif [17]. Pada hakikatnya ilmu fisika merupakan salah satu ilmu pengetahuan alam yang merupakan suatu proses dan produk yang mengaji tentang alam [18].

Selain itu, fisika juga merupakan mata pelajaran yang terdiri dari konsep-konsep dan paling banyak menyajikan rumus [19]. Sehingga mata pelajaran fisika merupakan salah satu mata pelajaran yang kurang disukai oleh kebanyakan peserta didik [20]. Fisika dianggap sulit karena pembelajaran fisika masih mengharuskan siswa untuk menghafal rumus-rumus yang abstrak [21].

Berdasarkan hasil wawancara yang dilakukan dengan salah satu seorang guru fisika didapatkan hasil bahwa masih banyak peserta didik yang kurang termotivasi untuk belajar fisika [22]. Tertarik atau tidak tertariknya peserta didik terhadap pelajaran fisika dapat terlihat dari kecenderungan peserta didik dalam menerima atau pun menolak ketika diminta untuk mengerjakan soal yang diberikan [23]. Selain itu, kesenangan belajar peserta didik terhadap pembelajaran fisika menjadi salah satu kunci efektivitas kegiatan belajar dan mengajar [24].

Salah satu aspek yang mempengaruhi sikap peserta didik terhadap proses pembelajaran fisika yaitu motivasi belajar. Dengan kurangnya minat dan motivasi siswa dalam memahami materi pelajaran fisika, itu akan berdampak pada hasil belajar peserta didik [25]. Motivasi belajar sendiri memiliki arti sebagai dorongan yang diberikan oleh seseorang untuk lebih giat dalam berusaha untuk mencapai apa yang diinginkan [13]. Motivasi belajar juga memegang peran penting dalam 
memberikan gairah atau semangat dalam melakukan proses belajar [26].

Masih lemahnya motivasi peserta didik untuk belajar fisika dikarenakan kurangnya pemahaman peserta didik tentang hakikat, kemanfaatan, keindahan serta lapangan pekerjaan yang dihasilkan dari belajar fisika [27]. Seorang siswa yang memiliki motivasi yang tinggi akan melakukan tugas dari guru sebaik mungkin [28]. Salah satu yang berpengaruh terhadap lemahnya motivasi siswa dalam belajar fisika yaitu hasil belajar [29].

Berdasarkan uraian di atas, penelitian ini bertujuan untuk memperoleh gambaran terkait dengan pengaruh motivasi belajar siswa terhadap hasil belajar siswa pada materi gerak lurus di SMAN 6 Muaro Jambi. Hasil peelitian ini dapat digunakan untuk meningkatkan motivasi belajar siswa terhadap pembelajaran fisika. Adapun hipotesis dalam penelitian ini yaitu terdapat pengaruh yang positif dan signifikan antara motivasi belajar siswa terhadap hasil belajar siswa kelas X IPA di SMAN 6 Muaro Jambi.

\section{METODE}

Penelitian ini dilaksanakan di Sekolah Menengah Atas Negeri 6 Muaro Jambi yang bertempatan di Desa Mudung Darat, Kec. Muaro Sebo, Kab. Mudung Darat. Penelitian dilaksanakan pada bulan Oktober 2020 secara online. Tujuan dari dilakukan penelitian ini yaitu untuk mengetahui pengaruh motivasi belajar siswa terhadap hasil belajar siswa pada mata pelajaran fisika di Sekolah Menengah Atas Negeri 6 Muaro Jambi. Metode yang digunakan dari penelitian ini adalah menggunakan penelitian kuantitatif dengan jenis penelitian survei. Dalam KBBI survei dapat diartikan sebagai suatu teknik penelitian yang secara jelas membatasi data yang akan dikaji dan diamati. Subjek dari penelitian ini adalah siswa Sekolah
Menengah Atas Negeri 6 Muaro Jambi angkatan tahun 2019/2020 yang berjumlah 50 siswa.

Teknik dari pengumpulan data pada penelitian ini yaitu menggunakan teknik purposive sampling. Penelitian dilakukan dengan cara mengumpulkan data menggunakan instrumen penilaian tes berupa kuisioner atau angket tentang motivasi belajar yang berjumlah 30 item ini menggunakan skala likert. Skala tersebut dari 4 poin dengan pernyataan positif nilai sangat setuju 4 , setuju 3 , tidak setuju 2 dan sangat tidak setuju 1. Sedangkan untuk bobot pernyataan negatif adalah 1 sangat setuju, 2 setuju, 3 tidak setuju, 4 sangat tidak setuju.

Selain itu, instrumen yang digunakan yaitu soal pilihan ganda yang berjumlah 25 item dengan materi gerak lurus. Kuesioner yang digunakan dalam penelitian kali ini yaitu kuesioner tertutup dimana peserta didik akan memilih dari serangkaian jawaban yang telah disediakan oleh peneliti. Dalam melakukan penelitian ini, langkah pertama yang harus dilakukan oleh seorang peneliti yaitu menyebarkan kuesioner secara online melalui google form karena dalam masa pendemi. Setelah melakukan penyebaran kuesioner akan diperoleh sebuah data yang diinginkan. Setelah mendapatkan data langkah yang harus dilakukan yaitu menganalisis data dengan menggunakan SPSS dengan analisis jenis regresi yang dilengkapi dengan penjelasan naratif. Salah satu tujuan penggunaan analisis regresi dalam penelitian ini adalah untuk memprediksi variabel terikat (Y) apabila variabel bebas (X) diketahui. Variabel bebas dalam penelitian ini yaitu variabel motivasi belajar peserta didik, sedangkan variabel terikatnya yaitu hasil belajar siswa dalam menyelesaikan soal fisika dengan materi gerak lurus.

\section{HASIL DAN PEMBAHASAN}


Motivasi belajar diukur dengn menyebarkan angket secara online melalui google form yang berjumlah 30 pernyataan ke siswa. Angket motivasi disebar dan di ukur untuk menganalisis kualitas motivasi belajar siswa kelas X IPA di SMAN 6 Muaro Jambi terhadap mata pelajaran fisika. Hasil kualitas motivasi belajar siswa dapat dilihat pada Tabel 1 di bawah ini.

Tabel 1. Kategori Motivasi Belajar Fisika

\begin{tabular}{ccccc}
\hline & Interval & Frekuensi & Persentase & Kategori \\
\hline \multirow{4}{*}{ Motivasi } & $30,0-52,5$ & 0 & 0,0 & Tidak baik \\
& $52,5-75,0$ & 0 & 0,0 & Cukup baik \\
& $75,1-97,5$ & 39 & 78,0 & Baik \\
& $97,6-125,0$ & 11 & 22,0 & Sangat baik \\
\hline
\end{tabular}

Berdasarkan hasil dari jawaban peserta didik pada Tabel 1, didapatkan hasil bahwa ada $0 \%$ siswa yang tidak baik atau dapat dikatakan tidak ada siswa yang tidak baik, ada $78 \%$ siswa yang terkategorikan baik atau sekitar 39 siswa yang dikategorikan baik, serta ada $22 \%$ atau sebanding dengan 11 siswa yang termaksud ke dalam kategori sangat baik. Jadi dapat dikatakan bahwa motivasi belajar peserta didik termasuk dalam kategori baik.

Adapun untuk mengukur hasil belajar peserta didik, di sini peneliti menggunakan soal tes yang memiliki jumlah 25 soal pilihan ganda. Kualitas hasil belajar peserta didik dapat dilihat pada Tabel 2 .

Tabel 2. Kategori Hasil Belajar Siswa

\begin{tabular}{ccccc}
\hline & Interval & Frekuensi & Persentase & Kategori \\
\hline & $25,0-45,0$ & 0 & 0,0 & Gagal \\
Hasil & $45,1-65,0$ & 2 & 4,0 & Kurang Baik \\
Belajar & $65,1-85,0$ & 41 & 82,0 & Cukup Baik \\
& $85,1-105,0$ & 7 & 14,0 & Baik \\
& $105,1-125,0$ & 0 & 0,0 & Sangat Baik \\
\hline
\end{tabular}

Dari Tabel 2 dapat terlihat bahwa hasil belajar siswa yang diukur menggunakan soal tes dengan materi gerak lurus mendapatkan hasil bahwa ada $4 \%$ atau sebanding dengan 2 siswa yang tergolong kategori kurang baik, $82 \%$ atau sebanding dengan 41 siswa yang tergolong cukup baik, dan ada $14 \%$ atau sebanding dengan 7 siswa yang tergolong baik. Berdasarkan uraian tersebut, dapat disimpulkan bahwa motivasi belajar siswa pada mata pelajaran fisika tergolong ke dalam kategori cukup baik. Dalam penelitian ini menggunakan uji normalitas, uji normalitas yang digunakan yaitu uji normalitas kolmogorov-smirnov.

Berdasarkan hasil uji normalitas, didapatkan nilai signifikannya adalah 0,806 dimana artinya nilai signifikannya lebih besar dari nilai taraf signifikan uji yang sudah ditetapkan yaitu 0,05. Jadi dapat dikatakan bahwa sampel yang digunakan dalam penelitian ini merupakan sampel yang berdistribusi normal.

Tabel 3. Uji Regresi Pengaruh Motivasi dan Hasil Belajar.

\begin{tabular}{|c|c|c|c|c|c|}
\hline \multirow[t]{2}{*}{ Model } & \multicolumn{2}{|c|}{$\begin{array}{c}\text { Unstandardized } \\
\text { Coefficient }\end{array}$} & \multirow{2}{*}{$\begin{array}{c}\text { Standardized } \\
\text { Coefficient } \\
\text { Beta }\end{array}$} & \multirow[t]{2}{*}{$t$} & \multirow[t]{2}{*}{ Sig. } \\
\hline & $B$ & Std.Error & & & \\
\hline (Constant) & 24,967 & 4,815 & & $-5,185$ & ,000 \\
\hline Motivasi & 1,076 &, 052 & ,949 & 20,843 &, 000 \\
\hline
\end{tabular}


Analisis data dalam penelitian ini menggunakan bantuan SPSS. Hasil analisis data yang disajikan pada Tabel 3. Hasil analisis regresi linier sederhana digunakan untuk mengetahui pengaruh variabel bebas (X) atau di sini disebut dengan variabel motivasi terhadap variabel terikat (Y) atau di sini disebut dengan variabel hasil belajar. Berdasarkan Tabel 3 pada kolom understandardized cooeficient yang berada pada bagian $\mathrm{B}$ menunjukkan bahwa pengaruh hasil motivasi siswa terhadap hasil belajar siswa, dimana persamaan antara keduanya dapat dituliskan sebagai berikut:

$$
\begin{aligned}
& \mathrm{Y}=\mathrm{a}+\mathrm{bX} \\
& \mathrm{Y}=24,967+1,076 \mathrm{X}
\end{aligned}
$$

Dari persamaan analisis regresi ini menunjukkan bahwa konstanta a memiliki nilai sebesar 24,967 yang berarti $Y$ atau bisa disebut dengan variabel hasil belajar akan senilai dengan 24,967. Sedangkan untuk koefisien regresi motivasi belajar fisika dilambangkan sebagai $b$ yang memiliki nilai sebesar 1,076, di sini berarti setiap ada peningkatan motivasi belajar sebesar satu persen maka akan mempengaruhi variabel hasil belajar fisika peserta didik sebesar $1,076 \%$. Berdasarkan Tabel 3 pada kolom sig didapatkan nilai sig nya sebesar 0,00. Jika dibandingkan antara nilai signifikan hitungnya dengan nilai sigifikan yang ditentukan berarti $(0,00$ $<$ 0,05). Hal ini menjelaskan bahwa terdapat pengaruh yang signifikan antara motivasi belajar dan hasil belajar siswa. Maka dari itu penelitian ini menunjukkan bahwa terdapat pengaruh yang kuat dan bernilai positif antara motivasi dan hasil belajar siswa kelas X di SMA N 6 Muaro jambi. Ini berarti dengan memberikan motivasi kepada peserta didik maka semakni baik juga hasil belajar peserta didik terhadap mata pelajaran fisika. Hal ini sesuai dengan yang telah dituliskan oleh [30] dimana dikatakan bahwa motivasi dalam mengikuti belajar dapat menentukan kualitas baik atau tidaknya dalam menggapai tujuan yang ingin dicapai. Ini berarti semakin besar motivasi belajar yang dimiliki peserta didik maka semakin besar pula kesuksesaan peserta didik dalam belajar, sehingga dapat menimbulkan dampak yang baik bagi peserta didik yaitu dalam meningkatnya hasil belajar peserta didik tersebut.

\section{SIMPULAN}

Berdasarkan analisis data didapatkan hasil bahwa untuk motivasi belajar dapat tergolong ke dalam kategori baik, dengan presentasi $78 \%$ dengan jumlah 39 siswa. Sedangkan untuk hasil belajar siswa dapat dikategorikan ke dalam kategori cukup baik dengan presentase $82 \%$ atau sebanding dengan 41 siswa yang tergolong cukup baik. Dengan menggunakan uji regresi didapatkan hasil bahwa terdapat pengaruh yang baik dan positif antara motivasi belajar peserta didik terhadap hasil belajar peserta didik.

\section{UCAPAN TERIMA KASIH}

Peneliti di sini mengucapkan terima kasih terutama kepada pihak dosen pengampu, serta terima kasih kepada guru fisika di SMA N 6 Muaro Jambi. Tidak hanya itu, peneliti juga mengucapkan terima kasih kepada responden serta kepada temanteman yang telah membantu dalam melakukan penelitian ini.

\section{DAFTAR PUSTAKA}

[1] A. Joneska, Astalini, dan N. Susanti. "Perbandingan Hasil Belajar Fisika Menggunakan Strategi Pembelajaran Crossword Puzzle dan Index Card Match Pada Materi Cahaya Kelas VIII SMP Negeri 3 Batanghari". J. EduFisika, vol. 01, no. 01, pp. 2831, 2016.

[2] D. A. Kurniawan, Astalini, dan N. Kurniawan. "Analisis Sikap Siswa SMP terhadap Mata Pelajaran IPA". Lentera Pendidik. J. Ilmu Tarb. dan Kegur., vol. 22, no. 2, p. 323, 2019. 
[3] Astalini, D. A. Kurniawan dan A. D. P. Astalini. "Identifikasi Sikap Implikasi Sosial dari IPA, Ketertarikan Menambah Waktu Belajar IPA, dan Ketertarikan Berkarir di Bidang IPA Siswa SMP Sekabupaten Muaro Jambi”. J. Tarbiyah Jurnal Ilm. Kependidikan, vol. 7, no. 2, pp. 93-108, 2018.

[4] E. Dwijayanti dan H. Pathoni. "Penerapan Strategi Pembelajaran Aktif Tipe Peer Lessons untuk Meningkatkan Aktivitas dan Hasil Belajar Siswa pada Materi Suhu dan Kalor Kelas Xa di SMAN 8 Kota Jambi”. J. EduFisika, vol. 01, no. 01, pp. 18-21, 2018.

[5] R. Maulana, Jufrida, dan H. Pathoni. "Upaya Meningkatkan Pemahaman Konsep Siswa Menggunakan Discovery Based Learning dengan Bantuan LKS Digital Materi Fluida Dinamika Kelas XI SMAN 11 Kota Jambi”. Gravity Jurnal Ilm. Penelit. dan Pembelajaran Fis., vol. 4, no. 2, pp. 67-81, 2018.

[6] D. A. Kurniawan, A. Astalini. N. Kurniawan, dan H. Pathoni. "Analisis Korelasi Sikap dan Disiplin Siswa terhadap IPA pada Siswa SMP di Provinsi Jambi”. Jurnal Pendidikan Fisika dan Keilmuan (JPFK), vol. 5, no. 2, pp. 59-71, September 2019.

[7] A. dan M. S. Barokah. "Pengembangan Media Pembelajaran Interaktif Fisika Berbasis Macromedia Flash pada Materi Termodinamika untuk SMA". $J$. EduFisika, vol. 8, no. 2, pp. 26-32, 2019.

[8] R. M. dan A. D. Astalini, D.A. Kurniawan. "Sikap terhadap Mata Pelajaran IPA di SMP Sekabupaten Muaro Jambi". J. Lentera Pendidik., vol. 21, no. 2, pp. 214-227, 2018.

[9] Z. P. Utama, Maison, dan A. Syarkowi. "Analisis Kemampuan
Bernalar Siswa SMA Kota Jambi”. $J$. Penelit. Pembelajaran Fis., vol. 9, no. 1, pp. 1-5, 2018.

[10] S. Barokah, Asrial, dan Maison. "Pengembangan Media Pembelajaran Interaktif Fisika Berbasis Macromedia Flash pada Materi Termodinamika untuk SMA". $J$. EduSains, vol. 8, no. 2, pp. 11-17, 2019.

[11] A. X. dan P. P. Jufrida, F. R. Basuki. "Pengembangan Buku IPA Berbasis Kearifan Lokal Jambi pada Materi Tekanan Serta Getaran dan Gelombang". Indones. J. Sci. Math. Educ., vol. 02, no. 3, pp. 287-297, 2019.

[12] D. A. Kurniawan, Astalini, dan L. Anggraini. "Evaluasi Sikap Siswa SMP terhadap IPA di Kabupaten Muaro Jambi". J. Ilm. DIKDAKTIKA, vol. 19, no. 1, pp. 124-139, 2018.

[13] W. R. Saputra, M. Hendri, dan T. Aminoto. "Korelasi Motivasi dan Hasil Belajar IPA Siswa Kelas VIII di SMP Negeri Se-kecamatan Jambi Selatan". J. Pendidik. Fisika, vol. 4, no. 1, pp. 36-45, 2019.

[14] D. A. Puspitasari, M. Hidayat, dan W. Kurniawan. "Pengembangan Modul Elektronik Fisika Berbasis Pendekatan Saintifik Materi Getaran Harmonis Menggunakan Kvisoft Flipbook Maker". J. EduFisika, vol. 4, no. 1, pp. 79-91, 2019.

[15] N. Kurnia, M. Hendri, dan H. Pathoni. "Hubungan Persepsi dengan Hasil Belajar Fisika Kelas X MIA di SMA Negeri 4 Kota Jambi dan SMA Negeri 11 Kota Jambi”. J. EduFisika, vol. 01, no. 02, pp. 55-63, 2016.

[16] F. H. Marbun, Nehru, dan A. Syarkowi. "Pengembangan Modul Praktikum Berbasis Inkuiri Terstruktur pada Mata Kuliah Elektronika Dasar 1 Program Studi Pendidikan Fisika Universitas 
Jambi”. J. EduFisika, vol. 02, no. 02, pp. 18-33, 2017.

[17] A. E. Purwanto, N. Susanti, dan M. Hendri. "Studi Perbandingan Hasil Belajar Siswa Menggunakan Media Phet Simulations dengan Alat Peraga pada Pokok Bahasa Listrik Magnet di Kelas X SmpN 12 Kabupaten Tebo". J. EduFisika, vol. 01, no. 01, pp. 22-27, 2016.

[18] M. O. Setia, N. Susanti dan W. Kurniawan. "Pengembangan Media Pembelajaran dengan Menggunakan Adobe Flash CS6 pada Materi Hukum Newton tentang Gerak dan Penerapannya". J. EduFisika, vol. 02, no. 02, pp. 42-57, 2017.

[19] D. C. Masyithah, Jufrida, dan H. Pathoni. "Pengembangan Multimedia Fisika Berbasis Model Pembelajaran Inkuiri Terbimbing dengan Menggunakan Adobe Flash CS6 pada Matei Fluida Dinamis untuk Siswa Kelas XI". J. EduFisika, vol. 02, no. 01, pp. 51-60, 2017.

[20] D. Oktaviana, Jufrida, dan Darmaji. "Penerapan RPP Berbasis Multiple Intelligences untuk Meningkatkan Aktivitas dan Hasil Belajar Fisika Siswa pada Materi Kalor dan Perpindahan Kalor Kelas X MIA 4 SMA Negeri 3 Kota Jambi”. $J$. EduFisika, vol. 01, no. 01, pp. 7-12, 2016.

[21] S. Astalini, D. A. Kurniawan. "Sikap Siswa terhadap Pelajaran Fisika di SMAN Kabupaten Batanghari”. $J$. Ilmu Pendidik. Fis., vol. 3, no. 2, pp. 59-64, 2018.

[22] D. S. Pasaribu, M. Hendri, dan N. Susanti. "Upaya Meningkatkkan Minat dan Hasil Belajar Fisika Siswa dengan Menggunakan Model Pembelajaran Talking Stick pada Materi Listrik Dinamis di Kelas X SMAN 10 Muaro Jambi". $J$. EduFisika, vol. 02, no. 01, pp. 61-
69, 2017.

[23] D. Astalini., Kurniawan. "Pengembangan Instrumen Sikap Siswa Sekolah Menengah Pertama terhadap Mata Pelajaran IPA". J. Pendidik. Sains, vol. 07, no. 1, pp. 17, 2019.

[24] A. dan N. K. D. A. Kurniawan, "Siswa terhadap Pelajaran IPA di SMP Kabupaten Muaro Jambi Provinsi Jambi”. Curricula J. Teach. Learn., vol. 4, no. 3, pp. 111-127, 2019.

[25] R. Dani, N. A. Latifah, dan S. A. Putri. "Penerapan Pembelajaran Berbasis Discovery Learning Melalui Metode Talking Stick untuk Meningkatkan Pemahaman Konsep Gerak Lurus". J. EduFisika, vol. 4, no. 2, pp. 24-30, 2019.

[26] R. S. Sitompul, Astalini, dan Alrizal. "Deskripsi Motivasi Belajar Fisika Siswa Kelas X MIA di SMAN 9 Kota Jambi". J. EduFisika, vol. 3, no. 2, pp. 22-31, 2018.

[27] T. Aminoto, R. Dani dan E. Yusversa. "Pengembangan Termometer Gas sebagai Alat Peraga Pembelajaran Pokok Bahasan Skala Suhu Mutlak". J. EduFisika, vol. 4, no. 2, pp. 48-55, 2019.

[28] Jufrida, F. R. Basuki, M. D. Pangestu, dan N. A. D. Prasetya. "Analisis Faktor yang Mempengaruhi Hasil Belajar IPA dan Literasi Sains di SMP Negeri 1 Muaro Jambi”. J. EduFisika, vol. 4, no. 2, pp. 31-38, 2019.

[29] C. Chotimah, M. Hendri, dan D. P. Rasmi. "Penerapan LKS Berbasis Inkuiri Terbimbing pada Materi Listrik terhadap Hasil Belajar Siswa Kelas IX SMPN 22 Kota Jambi”. $J$. Penelit. Pembelajaran Fis., vol. 9, no. 1, pp. 36-39, 2018.

[30] S. B. Djamarah, Psikologi Belajar. Jakarta: Rineka Cipta, 2011. 